This item was submitted to Loughborough's Research Repository by the author.

Items in Figshare are protected by copyright, with all rights reserved, unless otherwise indicated.

\title{
Trajectories and antecedents of integration in mergers and acquisitions: A comparison of two longitudinal studies
}

PLEASE CITE THE PUBLISHED VERSION

https://doi.org/10.1177/0018726716686169

PUBLISHER

SAGE (C) The Author(s)

VERSION

AM (Accepted Manuscript)

\section{PUBLISHER STATEMENT}

This work is made available according to the conditions of the Creative Commons Attribution-NonCommercialNoDerivatives 4.0 International (CC BY-NC-ND 4.0) licence. Full details of this licence are available at: https://creativecommons.org/licenses/by-nc-nd/4.0/

\section{LICENCE}

CC BY-NC-ND 4.0

\section{REPOSITORY RECORD}

Edwards, Martin R., Jukka Lipponen, Tony Edwards, and Marko Hakonen. 2019. "Trajectories and Antecedents of Integration in Mergers and Acquisitions: A Comparison of Two Longitudinal Studies". figshare. https://hdl.handle.net/2134/27627. 


\title{
Antecedents and trajectories of integration in mergers and acquisitions: A comparison of two longitudinal research studies
}

\begin{abstract}
Despite existing research examining snapshots of employee reactions to organizational mergers and acquisitions (M\&A), there is a complete absence of work theorizing or exploring rates of change in employees' organizational identification with the merged entity. We address this gap using two 3-wave longitudinal panel samples from different M\&A settings, tracking change in identification through a two-year period. Theorizing trajectories of change in identification across the organizations in both settings, we make predictions linked to expected antecedents of change in identification. Our research context (M\&A-1) involves a merger of three Finish universities tracking 938 employees from each organization in threewaves (9 months pre-merger to 24 months post-merger). Our second context (M\&A-2) involves a multinational acquisition tracking 346 employees from both the acquired and acquiring organization in three-waves (from 2-26 months post-acquisition). Using Latent Growth Modelling we confirm predicted trajectories of change in identification. Across both samples, a linear increase (across T1, T2 and T3) in justice and linear decrease in threat perceptions were found to significantly predict a linear increase in identification across the post-M\&A period. We discuss organizational identification development trajectories and how change in these two antecedents account for changes in identification across M\&A contexts.
\end{abstract}




\section{INTRODUCTION}

A merger and acquisition (M\&A) is an ideal change context in which to explore the notion that one's “identity moorings are planted in shifting sand” (Albert, Ashforth and Dutton, 2000, p.14). In an M\&A, that aspect of an employee's sense of self which involves a "sense of oneness", or identification, with his or her employer faces a fundamental shift. Longitudinal research into identification in M\&As is important, partly because identification is considered to be a key indicator of post M\&A integration and success (Cartwright and Cooper, 1993; Giessner, Horton and Humborstad, 2016; Teerikangas and Very, 2006; Van Dick, Ullrich and Tissington, 2006). However, the vast majority of previous research on employee integration and identification following M\&As uses cross-sectional methods (e.g. Boen, Vanbeselaere and Cool 2006; Giessner, 2011, Lipponen, Moilanen and Olkkonen, 2004; Terry et al 2001; Terry and Callan 1998; Van Knippenberg et al, 2002). This research often makes various untested assumptions concerning change in identification, with the narrative implying that identification changes following an M\&A. Of course cross-sectional research designs will struggle to provide evidence that supports theoretical assumptions implying change; to adequately explore change related assumptions longitudinal research designs are required (Ployhart and Vandenberg, 2010).

Despite this, very little research on M\&As involves a longitudinal exploration of change in employee identification. Guerrero (2008) presented aggregated "site level” means of identification with the acquiring and acquired firms in four waves across a 54-month period, although this was not strictly speaking a longitudinal panel study as employees were not tracked/each survey was cross-sectional. Gleibs, Noack, and Mummendey (2009) studied perceptions of 211 students in a two-wave before and after panel study of a university merger, and Gleibs, Mummenday and Noack (2008) tracked 156 students across three-waves following the same merger. In addition, Bartels, Ad Pruyn and de Jong (2009) tracked 99 
employees in a two-wave study through an organisational restructure/internal divisional merger (4 months before and 2 years hence).

Whilst these few longitudinal studies provide useful information to help us understand patterns of change in identification in a merger setting, there is still an absence of research in the literature that tracks/follows employees over time to explore change in identification when two or more separate organisations come together. Thus, despite several decades of research exploring reactions to M\&As, very little research provides any concrete information concerning the rate and nature of change in employee identification following an M\&A and what predicts these changes.

The more we know about predictors and trajectories of identification following M\&As, the more informed we will be concerning how firms can integrate. Moreover, we know that M\&As go through different stages, with different pressures from senior management and different concerns on the part of employees evident at different times. Using the analogy of marriage, Dooley and Zimmerman (2003) highlight a number of stages that occur both in marriages and in M\&As, ranging from partner selection, planning the marriage / merger, the event itself (the marriage or the conclusion of the deal), the 'honeymoon', and the need to resolve differences that emerge thereafter. While not all M\&As will go through all of these stages neatly or sequentially, it is nevertheless evident that different periods of an M\&A entail distinct concerns for employees. The absence of longitudinal research is clearly significant, therefore.

A further important element of our research design is its ability to compare across organizational contexts. M\&As come in a number of different forms: in some cases one party is evidently 'dominant' over the junior partner, while others can be characterised as close to a 'merger of equals'. Related to this, some M\&As involve an entirely new entity being created, 
while in others the merged firm bears the name and key features of the dominant firm. Also, while in some cases the senior management teams agree a 'friendly' deal, in others negotiations are concluded in a more 'hostile' manner. We might expect these features to shape how employees perceive the M\&A in general, and whether they identify with the merged firm in particular. The role of organizational context is, therefore, significant.

The current study helps fill a gap in the literature as it follows individual employees from five different organizations over a period of more than two years following a university merger (of three organizations) and a multinational acquisition (where a larger organization acquired another). The longitudinal element to the design enables us to explore predictors of change in employees' organizational identification across this period as well as trajectories of change in organizational identification through and beyond organizational integration. Moreover, the inclusion of two quite different contexts gives the design a strong comparative element, allowing us to test how differences in context affect the trajectories of identification following M\&A. No other study has such a clear longitudinal and comparative design.

\section{Antecedents of change in Post-merger identification}

Existing research exploring potential antecedents of identification points toward many possible factors that may help explain what influences changes in identification following an M\&A. A key element of a merger or acquisition as a research setting is the potential for uncertainty and the prospect of job threat; indeed Van Dick, et al. (2006) describe a postmerger setting as "Working under a black cloud” for employees. A long tradition of research suggests that the post M\&A context is one of turmoil and change (Cartwright and Cooper, 1993; Terry, Callan and Satori, 1996) and in such a setting we would expect a real change or fluctuation in factors influencing whether a person identifies with their new employing entity. Thus, in a dynamic and changing environment these antecedents may themselves be expected 
to change; thus hypotheses or propositions accounting for change in identification need to consider the potential relationships between change in antecedents of identification associated with this turmoil and change in identification itself. Here, we set out two key mechanisms that should influence change in post M\&A identification in the context of "working under a black cloud”. These are: 1) change in perceived threat and 2) change in justice perceptions.

\section{Change in Perceived Threat}

A central feature of a post M\&A context is that employees are likely to be faced with a period (often sustained) of threat regarding the future. Numerous authors have discussed the importance of experiences of threat and discontinuity being linked with identification in changing and tumultuous environments (van den Bos and Lind, 2002; Van Dick et al. 2006; Hogg, 2007). Importantly, M\&A are situations where a perceived threat of future employment is present and researchers have measured how stress, anxiety, and coping are related to job attitudes (Terry et al., 1996; Terry \& Callan, 1998) or post-merger identification (Amiot et al., 2007). Given such contexts of flux and turmoil, changes in perceptions of threat are likely to be an important factor in explaining change in organizational identification. Most studies that explore the relationship between threat and identification tend to find a negative relationship. For example, Guerrero (2008) found that aggregated (mean) “site level” organizational identification was negatively related to aggregated (mean) site level threat at various time points post-acquisition.

In explaining why we might expect a negative relationship between threat perceptions and identification we can draw on theory from the stress literature. Lazarus and Folkman (1984) suggested that when people are in a stressful situation they tend to appraise the situation as a threat or a challenge. Appraising a situation as a potential threat reflects a concern that this situation might cause harm to the individual (Bardi, Guerra and Ramdeny, 
2009). According to Fugate, Prussia and Kinicki (2012) threat appraisals give meaning to employees' experience of change by capturing an individual's perception of what is at stake. Existing research reveals that threat appraisals are related to both affective and behavioral employee reactions. For instance, threat appraisals predicted negative emotions and problemfocused coping (Scheck \& Kinicki, 2000), and forms of withdrawal-intentions to quit, voluntary turnover, and absenteeism (Fugate et al., 2012).

In organizational mergers the relationships between threat appraisal and forms of withdrawal can be explained, as individuals are likely to be motivated to avoid or mitigate threats; these motivations can manifest as intentions and actual behaviors. Reduced identification with the post-merger organization represents a form of psychological withdrawal, which is likely to mitigate perceived threat. Thus, whatever the M\&A context, we expect perceptions of threat to be salient and changing and hypothesize as follows:

Hypothesis 1 (H1): The greater the increase (positive change) in perceptions of threat (across T1, T2, T3) the greater the decline (negative change across T1, T2, T3) in post-merger OID.

\section{Change in Perceived Justice}

Perceived fairness has been acknowledged to be a crucial mechanism in explaining variation in levels of organizational identification, especially within the Social Identity Theory tradition (Tajfel and Turner, 1979). Authors have studied the effects of both distributive justice (the perceived fairness of resource allocation outcomes) and the effects of procedural justice (the perceived fairness of decision-making processes) (e.g. Edwards \& Edwards, 2012; Lipponen et al., 2004; Monin et al., 2014; Tyler \& De Cremer, 2005). The main emphasis in empirical studies has generally been on how fairness affects post-merger 
organizational identification (Amiot Terry and Callan., 2007; Giessner Viki, Otten, Terry, and Tauber, 2006; Gleibs et al., 2008).

Justice theories (e.g. the Group Engagement Model, Tyler \& Blader, 2003) inspired and anchored to Social Identity Theory emphasize that procedural justice in particular conveys important identity-relevant information and thus should be of critical importance in the development of post-merger identification. The crux of the theoretical explanation for why procedural justice perceptions (which we focus on here) should play a role in fostering identification revolves around the important information that fair treatment supplies to employees. Fair treatment provides information that employees are respected and that the organization can be trusted and is worthy of pride; these, in turn, build identification. Many cross-sectional studies in M\&A and in organizational change contexts (e.g., Amiot et al., 2007; Edwards \& Edwards, 2012; Lipponen et al. 2004; Michel et al., 2010) have found a link between justice and identification. Taking time and change into account in M\&A studies is, however, still very rare. The longitudinal three-wave study of a university merger by Gleibs et al. (2008) is an exception. Although their study uses students rather than employees as participants, the three-wave nature of their study means that their research can form a basis for establishing expectations of predictors of change in employees' identification post M\&A. Gleibs et al (2008) found that procedural fairness perceptions had a positive relationship with post-merger identification over time.

As Fortin, Cojuharenco, Patient and German (2014) emphasise, justice perceptions evolve over time; therefore, the knock-on effect of these perceptions should also vary across time. In an M\&A context, employees’ experiences across a period of organizational integration tend to involve a significant period of organizational change. Proponents of fairness heuristic theory (Van den Bos and Lind, 2002) argue that procedural justice perceptions are especially important to employees during dramatic organizational change as 
perceived fair treatment can help mitigate some of the negative uncertainties associated with change. Thus we expect that fairness perceptions are particularly important in influencing post-merger identification across whatever the organizational context as all organizations involved experienced change and uncertainty which procedurally just treatment is expected to mitigate. Therefore, we predict that:

Hypothesis 2 (H2): The greater the increase (positive change) in perceptions of procedural justice (across T1, T2, T3); the greater increase (positive change across T1, T2, T3) in post-merger organisational identification.

\section{The Contrasting M\&A Contexts}

As explained, the above hypotheses are to be tested in two rather contrasting settings. The first context (M\&A-1) involved the coming together of three Finnish universities. This was a ‘friendly' merger, while a new name and identity was created for the merged organisation and all employees became formally employed by this new entity post-merger. In M\&A-1, one university was approximately four times bigger (in terms of number of employees) than the two other (smaller) universities. The justification given for the merger was to improve the quality of research and education, whilst gaining synergies. Importantly, the threat of job loss was low as there were no lay-offs; although administrative staff experienced changes (some physical integration of central service offices occurred), research personnel experienced job continuity. The planning and announcement of the merger had commenced two years prior to data collection, by the time the research commenced (Time 1) the name of the new university was widely known, as was the merger date. Although the Time 1 data collection occurred 9 months before the merger officially took place, merger preparations were well under way and upcoming changes were visible to all employees. 
The other context (M\&A 2) involved a multinational acquisition within the manufacturing sector where the acquiring organization bought another multinational (both of which were US-owned) roughly half its size. There was little doubt that the larger firm was the 'dominant' one - the merged entity bore the acquirers name, for instance - and the deal had involved a period in which the bid was officially 'hostile'. The strategic reasons given for the acquisition were to expand the firm's product range and provide impetus for restructuring. These reasons for acquiring are likely to be common in acquisitions and the case can therefore be considered to be representative of a significant sub-set of acquisitions. Although, the acquiring employees experienced less change in terms of the identity of their employer compared to the acquired employees, restructuring and redundancies started in both of the two organizations almost immediately following the first phase of data collection (2 months post-acquisition). Most locations in both organizations lost a noticeable percentage of staff. Many lay-offs were made between T1 and T2, amounting to approximately 14\% of the combined workforce. These decisions continued to have an impact on staff between T2 and T3 (the workforce contracted by a further 11\%).

\section{Timescales and Trajectories of Employee Change in Identification in M\&A}

When theorizing the pace and patterns of expected change in identification following M\&A, we can envisage contrasting scenarios. One possible trajectory is for employees to be most positive about the new organization when they first join it. This may be because of the poor experiences prior to the merger or because of optimism concerning the prospects for the new entity. Their positive perceptions may then decline as the reality of organizational life sets in over time. This pattern of high initial levels followed by a decline has been termed the honeymoon and hangover effects (Boswell, Boudreau and Tichy, 2005; Boswell, Shipp, Payne and Culbertson, 2009). However, Boswell and colleagues’ work looked at organizational newcomers in general as opposed to being located in the context of M\&As, the 
relevance of which is that existing employees have generally been transferred involuntarily into the new entity in any M\&A setting (employees are not normally the people who make the decisions to move forward with an M\&A). Given this, their levels of identification may initially be lower than they experienced with their original organization. Indeed, in many cross-sectional studies, when pre-merger/acquisition identification is measured along with a measure of post-merger identification, the former is almost always higher than the latter, even when measured after the new entity is established (e.g. Amiot et al. 2007; Boen et al. 2006; Lupina-Wegener et al. 2013; Van Dick et al. 2004; Van Knippenberg et al. 2002). Given this pattern, it is reasonable to assume that just before or immediately post-merger or postacquisition, employees will have a low baseline level of identification with the new entity.

Hogg (2007, p.98) makes a key point that helps explain why identification with the immediate post M\&A organization is often low; "if the group prototype is fuzzy and unclear, lacks consensus...and information-poor ... we would be disinclined to identify”. To acquired employees, the new organizational entity is often unknown. Immediately after a merger or acquisition group “entativity” (Hogg and Adelmann, 2013) is likely to be low; the internal structure might not be clear, and the degree to which the new organization appears homogenous with shared goals and a common fate are likely to be low. To employees from constituent parts of a merger, the new entity is likely to appear to be made up of different groups of (potentially disparate) employees and (immediately following the merger at least) to be seen to be lacking in coherence. Potentially compounding this, there may also be a lack of available information about the new organization.

The aforementioned cross-sectional studies suggest that over time, employee levels of identification with the new entity will tend to rise. In the long-term, we expect to see an increase in identification as the new organization becomes more tangible as an entity and employees have had an opportunity to anchor their “need for belonging” (Baumeister and 
Leary, 1995). Ultimately, according to social identity theory we all have a need to belong, employers become a key source of satisfaction for this need (Ashforth and Mael, 1989) and as forging an identification with a stable entity can help us cope with a degree of uncertainty (Hogg, 2007) employees are expected to form such a psychological bond with their new employer over time.

However, we recognise that various factors and antecedents will influence the likelihood and speed of post M\&A identification recovery; in other words, the rate of eventual recovery is highly likely to have a number of contingencies, such as the degree to which their previous employing entity still exists (see Hornsey and Hogg. 2000). A crucial aspect of the context, which we might expect to influence rates of change in identification, are the differences between M\&A contexts. A number of authors (e.g. Aguilera and Dencker, 2004; Buono, Bowditch and Lewis, 1985; Giessner et al 2006) raise the issue that M\&As are not all the same and that different management strategies in M\&As may have distinct consequences for the likelihood of successful integration. Furthermore, the context is highly likely to be important in determining the rate of, and degree to which, employees begin to forge (or not) allegiances with the post merged entity. We use these contextual differences to help us theorize the expected rate and trajectory of change in employees’ organizational identification in each firm.

\section{Change in identification within M\&A 1}

Some mergers, of which M\&A 1 is an example, involve the coming together of two or more legal organizational entities to form a new organization. When this happens, employees from the all of the originally separate organizations are highly likely to experience an initial sense of discontinuity and a loss of organizational moorings (Van Knippenberg et al., 2002; Van Dick, et al. 2006), finding themselves employed by (often) a brand new unknown entity. 
Given this, we would expect in the current merger context, which involves three waves of measurement across 33 months (from a key period following formal announcement to 24 months post-merger), that levels of identification with the merged organizational entity should start low shortly after the merger plan has been finalised. At Time 1 of our merger study, whilst the name of the soon-to-be-merged entity had been agreed and plans were in place to begin integration, the employees were still employed in their separate university organisations. Thus we would expect employees' identification with the new entity to be low across the board at Time 1 given that the integration had formally occurred when the new identity is still in a state of low entativity. However, we expect levels of identification to increase across the next two years as the organization becomes concrete. This prediction also accords with Gleibs et al.’s. (2008) finding that students from both universities showed higher Time 3 post merger identification than at Time 1. Thus:

Hypothesis 3 (H3): There will be a significant general growth in identification with the merged organization across T1, T2 and T3

Although we are making a general prediction that in the time period of M\&A 1 employee identification should gradually increase, there are various features of the current context that enable us to make predictions about the rate of growth in identification after the merger was completed that distinguish between the separate organizational parties to the merger. It is very rare that a merger actually involves the coming together of genuine equals (Van Dick et al. 2006). In the current context, we had three organizations merging to make a new entity; however, one of these organizations is significantly larger than the other two and the new entity was made up of employees primarily (more than two-thirds) from this larger organization. Thus in the university merger one of the merger partners has a position of dominance (and potentially higher status) and the other two partners can be considered less dominant and potentially subordinate (using Gleibs, et al’s, 2008, terminology). 
Although existing research cannot provide us with definitive examples to enable us to predict the expected rate of change in employee identification, some theorizing can be drawn on to help us make propositions. In a context involving unequal sized merger partners, we might expect a difference in the rate of change in identification with a newly merged organization. As discussed by Van Knippenberg et al. (2002), employees working for the dominant partner are more likely to identify with the merged entity and Giessner et al. (2006, p.340) argue that a more influential partner in the merged organization is "much more likely to define the character of the merged company”. Therefore it would be reasonable to expect that employees from the larger partner (dominant group) in the merger would increase their identification at a faster initial rate (once the merger has occurred) than those from the smaller entities. While in the long-term employees from all of the university entities should all show increases (as with the Gleibs et al., 2008 study) in identification with the merged firm over time (from the low Time 1 base-line, regardless of which organization they originated from), we expect the growth trajectory to be different for the larger (more dominant) organization versus the smaller (less dominant) ones. Specifically, relative to the smaller organisations, we expect employees from the larger entity to show a steeper growth rate earlier in the process. Importantly, this implies a difference in curvilinear growth of identification over time because the initial trajectory of any change will be steeper with the larger entity before levelling out (thus any growth curve will be more convex in shape than that of the smaller entities, which will show a less steep growth over the initial period). Thus:

Hypothesis 4 (H4): When comparing employees from the two smaller universities with employees from the larger entity, there will be a significant difference in curvilinear change in identification with the post-merger organization across T1, T2 and T3; specifically we expect that the increase in post-merger identification to be steeper across the earlier time period with employees from the larger entity. 


\section{Change in identification within an M\&A-2}

As mentioned above, the second M\&A involves an acquisition in which the merged firm kept the name of the acquirer after acquisition. Although the acquired firm was allowed to maintain some form of "heritage" identity, all acquired employees were immediately given new contracts and e-mail addresses signifying their new employer. We were first granted access (T1) to a sample of both groups of employees two months after formal completion of the acquisition but before any major integration had occurred in earnest. In such a context we can make a number of predictions concerning immediate post-acquisition identification levels with the newly merged firm and expectations of trajectories of change in identification in the longer term. One source that is useful in this respect is research conducted by Guerrero (2008) who found identification levels to be high and largely stable with the acquiring firm with a slight increase in the final phase. With both acquired firms, however, identification levels were initially low but increased in the longer term.

Where an M\&A involves one party clearly being 'dominant' then employees from the acquired (or 'dominated') firm are likely, initially at least, to have a low level of identification with the acquirer. This group of employees is likely to experience identity related discontinuity (van Knippenberg et al., 2002) and possible severance of their “organizational moorings” (Albert et al, 2000). In situations where the post-acquisition merged firm maintains the acquirer’s identity, such as M\&A-2, employees from the acquiring firm should be able to transfer any existing pre-acquisition identification over to the newly merged firm that has the same name as their previous employer. We would therefore expect identification with the acquiring firm immediately after the acquisition to be higher among employees from the acquiring firm compared with those at the acquired. Thus: 
Hypothesis 5 (H5): Identification with the post-acquisition firm will initially (at Time 1) be higher with employees at the acquiring organization than with employees from the acquired entity.

In terms of trajectories of change, organizational identification levels at the acquiring firm should stay relatively stable (compared to the acquired employees). In contrast, we expect acquired employees to start with a low level of identification (relative to the acquiring group of employees) and this would gradually increase over time. Thus we are able to make the following prediction:

Hypothesis 6 (H6): There will be a significantly more positive linear growth in identification with the post-acquisition firm across T1, T2 and T3 with employees from the acquired organisation than with employees at the acquiring entity Whilst there are important contextual differences across the two samples utilized in the current study, there are key similarities in the research conducted across the two settings; across all organisations we measured identification, threat and justice in a three-wave longitudinal panel research design going beyond 24 months post M\&A. Originally, the research teams operated independently (and indeed in different countries), thus explaining certain differences in measures used for the study’s focal variables (details we now set out).

\section{METHOD}

\section{Procedures in the merger setting: M\&A-1}

The three waves of data collection were carried out across two years and nine months. Time 1 (T1) data collection occurred nine months before the official merger, two other rounds of data collection followed at 5-months (T2) and 24 months (T3) post-merger. The entire population of the 3 universities amounted to 3751 at Time 1 . We excluded 500 
employees who were (randomly) selected to take part in a separate survey. Thus our T1 target population involved 3251 employees. Of these, 1469 were returned. At T2 the population was again sent surveys and 1305 responded and at Time 3904 responded. As the analysis conducted can utilise data from two or more longitudinal waves we created a dataset that included employees who responded in two or more of the survey waves. In total, 350 employees responded to all questions used in the analysis at T1, T2 and T3. An additional 339 employees responded to the justice, threat or identification measures only at T1 and T2; another 117 responded at T1 and T3; and 132 responded at T2 and T3. Thus the total longitudinal sample used for the Latent Growth Modelling amounted to 938 employees (29\% of the target population). Of the final sample, 679 (72.4\%) respondents originated from the large university, 131 (14\%) and 128 (13.6\%) were from the two smaller universities. This was broadly representative of the proportions of all respondents who originated from these three organisations (72.6\%; $14.8 \%$ and $12.6 \%$ respectively). The final sample was made up of 473 (50.4\%) females and 465 (49.6\%) males, which only slightly under represented the proportion of males found in all respondents (which was 54\% in total).

\section{Procedures in the acquisition setting: M\&A-2}

The three waves of data collection spanned two years immediately following acquisition. Time 1 data collection occurred two months post acquisition and two further rounds (T2 and T3) of data collection followed with 12-month intervals. Online surveys were sent at $\mathrm{T} 1$ to all staff $(\mathrm{N}=893)$ at both the acquired and acquiring organizations in countries where the researchers gained access (UK, Netherlands and Sweden). In total 439 responses were returned (a 49\% effective completion rate). Due to layoffs, the target population fell to 771 between $\mathrm{T} 1$ and $\mathrm{T} 2$ and again to 683 between $\mathrm{T} 2$ and $\mathrm{T} 3$. The number of effective responses also fell to 407 at T2 (53\%) and 385 (56\%) at T3. As with the merger sample, we created a dataset that included employees who responded in two or more of the survey waves. 
In total, 187 employees responded to all questions used in the analysis at T1, T2 and T3. An additional 68 employees responded to the justice, threat or identification measures only at T1 and T2; another 46 responded at T1 and T3; and 45 responded at T2 and T3. Thus the total longitudinal sample used for the Latent Growth Modelling amounted to 346 employees (39\% of the Time 1 target population). The final sample was made up of 269 males (78.7\%) and 72 (21.1\%) females, which only slightly over represented the proportion of males found in all respondents (which was 76.5\% in total). In total, 212 (61.3\%) respondents originated from the acquirer and 134 (38.7\%) from the acquired, which was largely representative of the proportion found in all respondents (60.2\%:39.8\% respectively).

\section{M\&A-1: Measures}

Organizational Identification: The six-item Mael \& Ashforth (1992) measure was used to measure organizational identification with the merged organization. Example items include: "when someone criticises [merged organisation] it feels like a personal insult" and "[merged organisation's] successes are my successes”.

Procedural Justice: An 11-item justice measure was used across all three waves; the items were drawn (those appropriate to the context) from Moorman’s (1991) and Tyler and Blader's (2000) measure of procedural justice. These were introduced with a statement asking the respondents to consider how well the items described procedures in the foundation and preparation of the new organisation. Items were: "The rules and procedures have been applied consistently across people and situations”; "There has been a possibility for requests of clarification or additional information about decisions concerning the founding of the [merged organization]”; “All those affected by the decisions have been represented”; “The decisions have been based on accurate information”; “Opportunities have been provided to appeal or challenge decisions”; “All parties that are affected by the decisions have had 
opportunities to express their concerns"; "Feedback and information have been provided regarding the impacts of decisions"; "Employees have been treated with dignity during the founding process”; "In the founding process the rights of employees have been respected”; “The employees have been able to trust that the promises made are kept" and "Honest explanations have been given for the decisions made concerning the founding of the [merged organization]”.

Threat: A four-item scale was used to measure employees' experience of threat based on Bardi et al (2009), modified slightly for context. Items were: "I fear that I might not do well in [merged organisation]”; “There is a good chance that I might not adapt to working in [merged organisation]" "Many things could go wrong as a result of the founding of [merged organisation]; "I feel that difficulties could pile up so much that I might not be able to overcome them”.

\section{M\&A-2: Measures}

Organizational Identification: The five-item Mael and Ashforth (1995) scale was used to measure organizational identification; example items include: “when someone criticises [org] it feels like a personal insult” and “[org’s] successes are my successes”.

Procedural Justice: A four-item measure was used to tap perceptions of justice and referred to procedural justice or general perceptions of the fairness of the organization's procedures/policies (Folger \& Cropanzano, 1998). Items were based on Byrne’s (1999) measure and were: "I can count on [org] to have fair policies and procedures”, "When making decisions that concern me, [org] always uses fair procedures”, “[org] only uses just and fair procedures”, and “The policies and procedures at [org] are applied fairly”. 
Threat: A three-item scale was used to measure experiences of threat (based on Bartels et al., 2006), the measure was made up of the following items "I feel threatened by the integration of [acquirer org] and [acquired org]”, "I feel a sense of insecurity because of the integration of [acquirer org] and [acquired org]”, "I am worried about the impact that the integration of [acquirer org] and [acquired org] will have on my job”.

\section{Approach to Analysis}

A number of analytical steps were followed with data from both contexts. The first step involved CFA to test the measurement model with all constructs across the three waves (using Mplus 7.3). This testing involved, firstly, setting out the three-factor structural model (organizational identification, justice and threat) within each wave and comparing this with two and one-factor alternatives. Following this, a series of 9-factor models were tested across three waves separating all constructs whilst auto-correlated errors of measurement were allowed, linking repeatedly measured items; this was compared to a single factor model combining all items whilst allowing for auto-correlated errors. This procedure was followed with the full data set and repeated with the smaller list-wise panel.

Following confirmation of the study’s measures, reliability analysis was conducted and mean composites were constructed to form each variable. The study's main analysis was conducted using these composites. Firstly, zero-order correlations, means and standard deviations were produced (Tables 1 and 2). Following this we used two forms of analysis to test hypotheses 1-6. The main form of analysis that explicitly tests five of the six hypotheses is Latent Growth Modelling (LGM); this modelling enables us to test hypotheses 1, 2, 3, 5 and 6, which either involve predictions linked to a linear growth in our dependent variable of identification (1, 2, 3 and 6) or that there will be a difference in the T1 starting point of identification when comparing two of our organisations (Hypothesis 5). All of these 
hypotheses can be tested with LGM. However, as Hypothesis 4 involves a prediction that implies a difference in non-linear (quadratic) change over time when comparing two of our organisation types (small versus large university), an additional form of analysis is required because adding a quadratic slope to a three wave LGM leaves such a model under-identified (four or more waves are required to be able to test both linear and quadratic slopes with LGM, Newsom, 2015). Thus to test the difference in the linear and quadratic slope across the two organisation types we ran two 3 (within) by 2 (between) General Linear Model ANOVAs with T1, T2, and T3 identification as the repeated measures dependent variable in each of the contexts and small versus large university or acquirer versus acquired as the between group factor. Importantly, this additional analysis gives us an indication of whether there are general changes (linear or curvilinear - thus testing Hypotheses 3) over time across the two organisation types (Hypotheses 4 and 6) in each sample.

Latent Growth Modelling (LGM): As an extension of structural equation modelling, LGM analysis helps researchers model or assess change in levels of particular variables and it allows the exploration of different features of change in constructs measured over multiple time points; features such as the average initial status of each temporal measure, individual variation in this, average change over time along with individual variation in change over time (Bollen and Curren, 2006). Importantly, whilst LGM does not provide strict evidence of causality it can be considered a stronger causal design than cross-sectional designs because it enables researchers to examine how initial levels and change in variables (over time) are related to change in other constructs over time, and indeed whether initial levels and change in particular variables are related to initial levels and change in others (Ng and Feldman, 2013). Initially we tested univariate unconditional models to explore each of our longitudinal variables (threat, justice and identification) in turn. We tested for significant variation in individuals’ Time 1 starting points (random intercept); a significant mean slope/rate of 
change over time in the variables (fixed slopes); significant variation in individual rates of change (random slope) in each of these variables over time and whether there was a significant covariance in the mean intercept and the mean slope factor/change over time. In setting these models (following procedures set out in Duncan, Duncan and Strycker, 2006) the loadings from the intercept factor on each of the repeated measures are fixed at 1.0 and the loadings from the slope factor on the three repeated measures are fixed with values of 0,1 and 2. With our analysis, we then conduct multivariate LGM where we set the starting points/intercepts and growth/change factors of our independent variables (threat and justice) to predict the starting points/intercepts and growth/change in our dependent variable of identification (thus testing Hypothesis 1 and 2); in these LGM models we also include the organisational context dummy variable as a predictor of starting points/intercepts and growth/change in identification. If the organisational context dummy (as a covariate) is found to predict the starting point of identification, this in effect indicates a significant difference in the starting point of identification across the organisational categories (testing Hypothesis 5); if the organisational context dummy (as a covariate) is found to predict the identification slope factor, this will indicate that the slope, or change over time, is significantly different across the organisational categories (testing Hypothesis 6). One of the advantages of LGM analysis is that where there are instances of individual respondents not having replied in all the waves, the remaining data available can still be utilised. Thus we were able to include any individual that had completed the questionnaire over at least two of the three time points. As there was some potential for missing data to be linked to features of the merger and acquisition context, the model of estimation used to enable this was maximum likelihood estimation under a MAR (Missing At Random) function (which, despite its name, actually assumes that some variables may be related to inclusion/non-inclusion in the longitudinal study, Little and Rubin, 2002) rather than a MCAR (Missing Completely At Random) 
function which assumes complete randomness to any missingness. As Schafer and Graham (2002) argue, MAR assumptions are appropriate in longitudinal studies where further followup data is not collected with non-respondents; as Collins, Schafer, and Kam (2001) have demonstrated, even where the assumptions of MAR were incorrect the impact on estimates and standard errors should be minor.

\section{RESULTS}

Descriptive Statistics: M\&A-1 and M\&A-2

Tables 1 and 2 show the zero-order correlation coefficients between the three focal variables across and within the three waves in both the merger (Table 1) and the acquisition (Table 2) context using the three wave list-wise deleted panel samples (participants who responded to every single questionnaire item across all three waves). All scales show good reliability (all Cronbach Alphas are above 0.70) and the correlations are in the expected direction (e.g. justice is positively correlated with identification which is negatively related to threat perceptions). In the merger setting (M\&A-1), the means also show a general trend that would be expected in the context, with identification generally increasing over time, threat increasing over the three waves; justice is more variable over the three-waves. The means in the acquisition sample (M\&A-2) also show a general trend that would be expected in the context, with identification generally increasing over time, justice increasing over time, with threat decreasing over the three waves of data collection.

Insert Tables 1 and 2 about here

\section{M\&A-1: Measurement Model Testing in the merger context}


The strict list-wise deleted three-wave panel dataset included 350 respondents with the merger dataset, the actual dataset utilised in LGM included employees who responded across two or more waves of items (either T1 and T2, T2 and T3, T1 and T3 or T1, T2, and T3); thus larger samples (than the $\mathrm{N}=350$ list-wise panel) were utilised from each wave $(\mathrm{T} 1=\mathrm{N}$ of 806; $\mathrm{T} 2=\mathrm{N}$ of $821 ; \mathrm{T} 3=\mathrm{N}$ of 599$)$. CFA was conducted on these fuller datasets to ensure measurement model integrity on these samples. A three-factor model was tested with identification (6-item), justice (11-item) and threat (4-item) set as separate factors in each wave. At each time point the three-wave three-factor models showed good to acceptable fit with the data $\left(\mathrm{T} 1: x^{2}=886.10, \mathrm{df}=186, x^{2} / \mathrm{df}=4.76, \mathrm{SRMR}=0.06, \mathrm{RMSEA}=0.07, \mathrm{CFI}=0.90\right.$, $\mathrm{TLI}=0.89 ; \mathrm{T} 2: x^{2}=916.12, \mathrm{df}=186, x^{2} / \mathrm{df}=4.93, \mathrm{SRMR}=0.06, \mathrm{RMSEA}=0.07, \mathrm{CFI}=0.91$, $\mathrm{TLI}=0.89 ; \mathrm{T} 3: x^{2}=683.37, \mathrm{df}=186, x^{2} / \mathrm{df}=3.67, \mathrm{SRMR}=0.05, \mathrm{RMSEA}=0.07, \mathrm{CFI}=0.91$, TLI=0.90). In addition to these analyses, nine two-factor models were tested (three at each time point) combining two of the three variables as well as three one-factor within-wave models. Importantly on each occasion the three-factor models fit the data significantly better ( $x^{2}$ difference $\mathrm{p}<0.001$ ) than one or two-factor models in each wave. As an additional check for measurement model integrity the same tests were conducted on the list-wise deleted dataset of $\mathrm{N}=350$ and on every occasion the 3-factor models showed significantly better ( $<<0.001$ with every comparison) fit than any one or two-factor combination.

A 9-factor three-wave model was tested on the extended dataset separating all within and across wave constructs - whilst allowing for correlated errors across repeated items; this 63 item model fit the data well $\left(x^{2}=3870.84, d f=1791, x^{2} / d f=2.16, S R M R=0.05\right.$, $R M S E A=0.04, C F I=0.92, T L I=0.91)$ significantly better $\left(x^{2}\right.$ difference $\left.\mathrm{p}<0.001\right)$ than a single factor model which grouped all constructs into one conglomerated structure $x^{2}=11611.41$, $d f=1827)$. We also examined whether these measures demonstrated longitudinal measurement invariance (Vandenberg and Lance, 2000). On the basis of chi-square 
difference tests, we found that the organisational identification scale items demonstrated fullmetric invariance, as did the justice measures $\left(x^{2}\right.$ difference for free versus invariant models, $\mathrm{p}>0.05$ ). There was some evidence of metric variance with the threat measure ( $x^{2}$ difference for free versus invariant models, $\mathrm{p}=0.043$ ); if one adjusts the target $\mathrm{p}$-value cut-off to take into account family wise error with 3 comparisons this becomes non-significant. The metric invariance tests with all measures were, therefore, deemed to be acceptable and all factor loadings showed the same pattern of loadings on all items across each wave.

\section{M\&A-1: Measurement model testing in the acquisition context}

In the acquisition context a list-wise deleted three-wave panel dataset included 187 respondents. The actual dataset utilised in LGM included employees who responded across two or more waves of items; thus larger samples were utilised from each wave (T1=N of 301; $\mathrm{T} 2=\mathrm{N}$ of $300 ; \mathrm{T} 3=\mathrm{N}$ of 278 ) and CFA was conducted on these fuller datasets. A three-factor model was tested with identification (5 items), justice (4 items) and threat (3 items) set as separate factors in each wave. At each time point the three-wave three-factor models showed good to acceptable fit with the data $\left(\mathrm{T} 1: x^{2}=63.04, \mathrm{df}=51, x^{2} / \mathrm{df}=1.24, \mathrm{SRMR}=0.03\right.$, RMSEA=0.03, CFI=0.99, TLI=0.99; T2: $x^{2}=74.51, \mathrm{df}=51, x^{2} / \mathrm{df}=1.46, \mathrm{SRMR}=0.04$, RMSEA=0.04, CFI=0.99, TLI=0.98; T3: $x^{2}=113.51, \mathrm{df}=51, x^{2} / \mathrm{df}=2.26, \mathrm{SRMR}=0.06$, RMSEA=0.07, CFI=0.97, TLI=0.96). As with M\&A-1,, nine two-factor models were tested (three at each time point) combining two of the three variables in turn as well as three one factor models within each wave; on each occasion the three-factor models fit the data significantly better $\left(x^{2}\right.$ difference $\mathrm{p}<0.001$ ) than one or two-factor models in each wave. Again all of these tests were repeated on the list-wise deleted dataset of $\mathrm{N}=187$ and on every occasion the 3-factor models showed significantly better fit $(\mathrm{p}<0.001$ with every comparison than any one or two-factor combination. 
A 9-factor three-wave model was tested on the extended dataset the separating all within and across wave constructs - whilst allowing for correlated errors across repeated items; this 36 item model fit the data well $\left(x^{2}=777.51, d f=523, x^{2} / d f=1.49\right.$, SRMR=0.03, $R M S E A=0.04, C F I=0.99, T L I=0.98)$ significantly better $\left(x^{2}\right.$ difference $\left.\mathrm{p}<0.001\right)$ than a single factor model which grouped all constructs into one conglomerated structure. We found that the organisational identification scale items and the justice items demonstrated full-metric invariance ( $x^{2}$ difference for free versus invariant models, $\mathrm{p}>0.05$ ). While there was some evidence of variation in the metric variance with the threat measure $\left(x^{2}\right.$ difference for free versus invariant models, $\mathrm{p}<0.05$ ), this was deemed to be acceptable as all factor loadings were above 0.88 on all items across all waves and as Ng et al (2010) and Pentz and Chou (1994) argue, partial metric invariance does not pose a major threat to interpretation of longitudinal results.

\section{EXAMINING MEAN LEVELS ORGANIZATIONAL IDENTIFICATION (TIME 1,}

\section{TIME 2 and TIME 3)}

\section{M\&A-1: Mean levels of identification with the merged university organisation}

A 2 (between) X 3 (within) ANOVA was conducted to test the temporal changes in identification across the two organization types (large versus smaller organisational entity). In this and subsequent analyses, the two smaller organizations were combined to form a comparator group to the larger of the three organizations. Identification showed a linear growth over time $(\mathrm{F}=41.52, \mathrm{p}<0.001)$, supporting Hypothesis 3; means started at 2.63 for $\mathrm{T} 1$, 2.79 at $\mathrm{T} 2$ and 2.91 at T3. There were no general curvilinear changes over time $(\mathrm{F}=0.214$, $\mathrm{p}>0.05)$, and no overall differences in identification $(\mathrm{F}=1.292, \mathrm{p}>0.05)$ between the two organization types. The marginal mean in identification for the large organization (2.81) was similar to that of the grouped two smaller organizations (2.72). There was not a significant 
difference in the linear changes in identification between the two organization types $(F=0.073, p>0.05)$, both showed an increase across the three waves. However, the larger of the organization types showed a steeper increase between T1 to T2 (T1 mean=2.64, T2 mean=2.86, T3 mean=2.92) than the smaller organizational grouping, which showed a steeper increase from T2 to T3 (T1 mean=2.63 T2 mean=2.64, T3 mean=2.88, supporting Hypothesis 4). The ANOVA shows that these varying quadratic trajectories are significantly different across the two organization types (quadratic interaction, $F=11.65, p<0.01$, Figure 1 ).

Insert Figure 1 about here

\section{M\&A-2: Mean levels of identification with the private sector acquisition}

A 2 (between) X 3 (within) ANOVA was conducted to test the mean patterns of identification with the acquirer versus acquiring organizations across the 3 waves. Identification across the entire sample changed significantly $(\mathrm{F}=15.12, \mathrm{p}<0.001)$ in a linear fashion over time with means starting at 3.31 for T1, rising to 3.41 at T2 and 3.44 at T3. There were no general curvilinear changes over time $(\mathrm{F}=1.65, \mathrm{p}>0.05)$. There was an overall difference in identification $(\mathrm{F}=4.46, \mathrm{p}<0.05)$ between the acquirer versus acquiring organization, the acquirer marginal mean (3.45) being higher than that of the acquired (3.26). There was a significant difference in linear changes in levels of identification between the two organization types $(\mathrm{F}=13.54, \mathrm{p}<0.001)$, with a greater linear increase in identification at the acquired organization ( $\mathrm{T} 1$ mean=3.06, $\mathrm{T} 2$ mean=3.31, T3 mean $=3.42$, supporting Hypothesis 6) than the acquiring organization which showed a relatively stable level of identification across the three waves ( $\mathrm{T} 1$ mean=3.44 $\mathrm{T} 2$ mean=3.46, $\mathrm{T} 3$ mean=3.45), see 
Figure 2. No variation in quadratic trajectories across the two organizations was found (quadratic interaction effect $\mathrm{F}=0.55, \mathrm{p}>0.05$ ).

Insert Figure 2 about here

\section{UNIVARIATE LATENT GROWTH MODELS}

In each sample we initially explored a null LGM which produced parameters of mean Initial Status (IS) for each variable then tested for the significance of allowing individuals to vary (random effects) on these starting points (producing an IS variance figure). Thereafter, parameters were produced to obtain an indicator of any significant mean level of Change (CH) from this starting point over time (fixed effects) and tested for the significance of allowing individuals to vary (random effects) on these changes over time, along with the covariance between the IS and $\mathrm{CH}$. In both of our samples, with all of the longitudinal variables (organisational identification, justice and threat) the Initial Status varied significantly across individuals, there were significant mean linear changes from these starting points across the sample and individuals varied significantly in these slopes over time. We set out the random and fixed effect parameters on the final univariate LGM growth models in Tables 3 and 4 (unstandardized coefficients for means, variance, co-variance and change coefficients are presented in these univariate models).

\section{M\&A-1: The Merger Context}

With the merger sample (M\&A 1), we examined the mean initial starting point and slope factors of all three of the study variables. With Identification, the estimated mean intercept/Initial Status (IS) was $2.70(\mathrm{p}<0.001)$ and estimated mean slope (change $-\mathrm{CH}$ ) is 
$0.12(\mathrm{p}<0.001)$ suggesting an aggregate growth over time (thus supporting Hypothesis 3$)$. Significant estimates of the mean slopes here indicate an overall change in these variables across time. However, the LGM analysis also indicates that employees varied significantly across the Initial Status for identification (variance IS=0.41, $\mathrm{p}<001$ ) and individuals also varied significantly in growth patterns (variance $\mathrm{CH}=0.05, \mathrm{p}<001$ ). Interestingly the covariance of the IS and $\mathrm{CH}$ for identification was not significant (covariance=-0.01). With Perceived Justice, the estimated mean intercept/initial status (IS) is $2.77(\mathrm{p}<0.001)$ and estimated mean slope is $-0.11(\mathrm{p}<0.001)$, suggesting an overall decrease over time. With the justice measures, employees varied significantly across the Initial Status (variance IS $=0.31$, $\mathrm{p}<001$ ) and individuals also varied significantly in growth patterns (variance $\mathrm{CH}=0.05, \mathrm{p}<001$ ). The co-variance of the IS and $\mathrm{CH}$ for justice was significant (covariance $=$ 0.03, $\mathrm{p}<0.05$ ), suggesting that employees with higher initial ratings of justice showed a greater decrease over time in justice judgments. With perceived threat, the estimated mean intercept is $2.37(\mathrm{p}<0.001)$ and estimated mean slope is $0.11(\mathrm{p}<0.01)$ suggesting a significant overall growth in threat over time; however individual employees varied significantly across the Initial Status of threat (variance IS=0.33, $\mathrm{p}<001$ ); individual growth patterns also varied significantly (variance $\mathrm{CH}=0.04, \mathrm{p}<001$ ). The co-variance of the IS and $\mathrm{CH}$ for threat was not significant (covariance $=0.00)$.

Table 3 about here

\section{M\&A-2: The Acquisition Context}


In the acquisition context (M\&A 2), we again examined the mean initial starting point and slope factors of all three of the study variables. With Identification, the estimated mean intercept/Initial Status (IS) was $3.26(\mathrm{p}<0.001)$ and estimated mean slope (change $-\mathrm{CH}$ ) is $0.06(\mathrm{p}<0.01)$, indicating a significant overall growth in identification over time. Employees varied significantly across the Initial Status for identification (variance IS $=0.40, p<001$ ) and individuals also varied significantly in growth patterns (variance $\mathrm{CH}=0.05, \mathrm{p}<001$ ). The covariance of the IS and $\mathrm{CH}$ for identification was significant (covariance $=-0.06, \mathrm{p}<0.001$ ) suggesting that those with lower IS of identification tended to show an increase in this over time. With perceived justice, the estimated mean intercept/initial status (IS) is $3.25(\mathrm{p}<0.001)$ and estimated mean slope is $0.07(\mathrm{p}<0.01)$ indicating an overall significant growth in justice overtime. Employees varied significantly across the justice Initial Status (variance IS $=0.31$, $\mathrm{p}<001$ ); and with individual growth/change in justice patterns (variance $\mathrm{CH}=0.05, \mathrm{p}<01$ ). The co-variance of the IS and $\mathrm{CH}$ for iustice was not significant (covariance $=-0.03, \mathrm{p}>0.05$ ). For the threat measures, the estimated mean intercept/initial status (IS) is $2.71(\mathrm{p}<0.001)$ and estimated mean slope is $-0.18(\mathrm{p}<0.001)$, suggesting a significant overall reduction slope in threat over time. Importantly employees varied significantly across the Initial Status of threat (variance IS=0.53, $\mathrm{p}<001$ ) and individuals varied significantly with changes in threat over time (variance $\mathrm{CH}=0.06, \mathrm{p}<001$ ). The co-variance of the IS and $\mathrm{CH}$ for threat was significant $(\mathrm{cov}=-0.13, \mathrm{p}<001)$ suggesting that employees with higher threat IS showed a greater decrease in this over time.

Insert Table 4 about here 


\section{MULTIVARIATE LGM MODELS PREDICTING INITIAL STATUS AND CHANGE IN IDENTIFICATION}

As mentioned above, to examine Hypotheses 1 and 2 we also examined multivariate latent growth models where we set the starting points/intercepts and growth/change factors of our independent variables (justice and threat) to predict the starting points/intercepts and growth/change in our dependent variable of identification. In these LGM models we also include the organisational context dummy variable as a predictor of starting points/intercepts and growth/change in identification (thus testing hypotheses 3, 5 and 6; note that Hypotheses 4 cannot be tested using an LGM with 3 waves, as such we rely on the $2 \mathrm{X} 3$ ANOVA results for this). As we are presenting structural predictors across different variables, standardized coefficients are presented with these LGM multivariate models.

\section{M\&A-1: The Merger Context}

Our multivariate LGM model predicting intercept/Initial Status (IS) and slopes/Change (CH) in identification in the merger context from the IS and $\mathrm{CH}$ of justice and threat as well as the Small Versus Large organisational control showed that a reduction in threat was associated with an increase in post-merger identification (Beta=-0.67, $\mathrm{p}<0.001$, supporting Hypothesis 1) and that a growth in justice was associated with an increase in identification (Standardized Beta=0.76, $\mathrm{p}<0.001$, supporting Hypotheses 2). In addition, those who perceived a high Initial Status of justice tended to show a greater initial status in identification (Beta $=0.57$, $\mathrm{p}<0.001$ ); justice IS was not however related to identification $\mathrm{CH}$ over time (Beta=0.09, $\mathrm{p}>0.05$ ). Initial levels of threat were not related to identification initial status (Beta=-0.010, $\mathrm{p}>0.05$ ) or change in identification over time (Beta $=0.03, \mathrm{p}>0.05)$. The small versus large organisational control did not predict initial status of identification (Beta $=-0.07, \mathrm{p}>0.05)$ or a linear change in identification over time (Beta $=0.05, \mathrm{p}>0.05)$. The model controlled for 
covariance of initial status of justice and threat (Beta $=-0.65, \mathrm{p}<0.001$, showing that employees with higher initial status of threat reported lower levels of justice) and covariance of initial status and change in justice (Beta=-0.31, $\mathrm{p}<0.001$ ) as well as covariance of initial status and change in threat (Beta=-0.01, $\mathrm{p}>0.05$ ). The model fit of this multivariate LGM was shown to be acceptable $\left(x^{2}=325.431, \mathrm{df}=38, x^{2} / \mathrm{df}=8.56\right.$, SRMR=0.07, RMSEA=0.09, $\mathrm{CFI}=0.90, \mathrm{TLI}=0.88)$.

Insert Table 5 about here

\section{M\&A-2: The Acquisition Context}

Our multivariate LGM model predicting Initial Status and Change in identification in the acquisition context from the IS and $\mathrm{CH}$ of justice and threat as well as the Acquirer versus Acquired organisational control showed that a reduction in threat was associated with an increase in post-merged (acquirer and acquired) organisational identification (Beta=-0.63, $\mathrm{p}<0.001$, supporting Hypothesis 1). In addition, a growth in perceived procedural justice was associated with an increase in post-acquisition identification (Beta $=0.73, \mathrm{p}<0.001$, supporting Hypotheses 2). In addition, those who perceived a high initial level of justice tended to show a greater initial status in identification (Beta $=0.57, \mathrm{p}<0.001$ ); justice IS was not however related to change in identification over time (Beta $=0.17, \mathrm{p}>0.05$ ). Initial status of threat was not related to initial status in identification (Beta=-0.01, $\mathrm{p}>0.05$ ); however employees with higher initial status of threat reported lower levels of identification as time went on (Beta=-0.50, $\mathrm{p}<0.01$ ). The organisational context dummy (acquired versus acquiring firm) path showed a significant relationship with the identification intercept/initial status, 
(Beta=-0.40, $\mathrm{p}<0.001$ ); thus, employees from the acquired firm showed significantly lower initial status of identification compared to the acquired employees (the acquired firm has the lower coding, thus the negative Beta indicates that acquired employees show significantly less initial levels of identification), which supports hypotheses 5. Also, the organisational context dummy path showed a significant relationship with the identification slope factor (Beta=0.46, $\mathrm{p}<0.001$ ), thus employees from the acquired firm demonstrate a significantly more positive linear growth over time compared to those from the acquiring firm (supporting hypothesis 6). The model controlled for covariance of initial status of justice and threat (Beta $=-0.30, \mathrm{p}<0.001$, showing that employees with higher initial status of threat reported lower levels of justice) and covariance of initial status and change in justice (Beta=-0.29, $\mathrm{p}<0.001)$ as well as covariance of initial status and change in threat (Beta $=-0.70, \mathrm{p}<0.001)$. The model fit of this multivariate LGM was shown to be approaching acceptable levels of fit $x^{2}=162.15, \mathrm{df}=38, x^{2} / \mathrm{df}=4.27, \mathrm{SRMR}=0.108, \mathrm{RMSEA}=0.097, \mathrm{CFI}=0.88, \mathrm{TLI}=0.86$ ).

Insert Table 6 about here

\section{DISCUSSION}

Understanding how and why employees respond to a merger or acquisition is of particular importance in understanding what leads to successful post M\&A integration; it is only through tracking employees during the period following M\&As that we can explore employee responses fully. Moreover, the trajectories of identification are shaped by the nature of the M\&A and by the position of the parties in relation to one another. Our longitudinal and comparative design enables us to explore change in employees’ 
organizational identification in a way that is sensitive to these shifting contexts; no other study has done this.

A number of important findings are uncovered in this study that can be grouped into two main categories. First, we show that regardless of the type of M\&A, change in the two central antecedents (increasing justice perceptions and decreasing perceived threat) can account for a growth in employee identification during the post-acquisition period. These findings help us explain which general change experiences are likely to drive change in employees’ psychological bonding with the merged entity. This is an important finding; the fact that we find this pattern across the two quite different M\&A contexts helps us confidently assert that change in procedural justice perceptions and threat appraisals will be key in determining whether employees successfully integrate post M\&A.

A key finding from both longitudinal samples in our study is that the initial status of justice perceptions are not related to a change in identification over time but a change/increase in justice perceptions over time was related to a change/increase in identification across the post-M\&A period. Also, in our university merger setting, the initial level of threat perceptions was not related to a change/increase in organisational identification over time but a change/decrease in threat clearly was. This highlights the importance of carrying out research involving longitudinal IV and DV panel designs in exploring post M\&A integration; such an observation could not have been discovered using cross-sectional methods or even methods that tracked employees over time but measured IVs at one point and DVs at a later point. Interestingly, in our multinational acquisition context, the initial level of threat perceptions was significantly related to a decrease in organisational identification. One of the differences across our two research settings is that there were layoffs in the multinational acquisition while in the university merger context there were not, and it is possible that fear of losing a job may have different effects than the less severe 
threats present in our merger context. Therefore, in future it would be important to take into consideration the qualitative differences in the nature of the threat, which may not be fully captured by our current measures.

Our second main category of findings relate to our ability to make predictions about the trajectories and patterns of change expected in post M\&A identification and how these are shaped by the M\&A context. In the university merger context, we see a general growth in identification with the merged entity across time. This can be partly explained by the fact that in the initial stages of the merger, the organizational entativity conditions - which Hogg (2007) suggests is a required condition for identification to develop - are low. Thus our finding of low identification with the new entity at this point makes sense in the particular merger context, and the general (main effect) growth in employees' levels of identification with the merged entity also makes sense as it becomes more concrete. The trajectory of change identification with the merged entity is, however, different when comparing employees originating from the larger versus the smaller universities. We see a steeper increase in identification levels among employees from the larger entity in the early period, while those from the smaller universities show a steeper increase later in the process. This supports our theorising that larger and more influential groups more readily identify with a merged entity. By the 24-month post-merger time point, the levels of organizational identification with the merged university had converged across the three sets of employees.

In our multinational acquisition context, our theorised trajectories of change in identification across the 24 month time period following the multinational acquisition have also been supported. We find a large initial gap in levels of identification when comparing the acquired versus the acquiring group of employees; the former show much lower initial levels of identification with the post-acquisition firm. For acquired employees, the nature of the new merged entity is initially an unknown and the merged organization is likely to be low in 
organizational entativity conditions for these employees (as the boundaries, its structure and the extent of shared goals may be unclear or in doubt). Over time, however, employees from the acquired firm show a significantly more positive linear increase than do employees from the acquiring organization.

Whilst we predicted (and found) this pattern of results in the acquisition context, it is of course conceivable that in some $M \& A$ contexts employees take longer to transfer their allegiances to their new employer. It is likely that the identification transference of the acquired employees in the current study was aided by the fact that they were able to maintain some aspect of their previous “heritage” identity. According to Hornsey and Hogg (2000), such a condition is important in creating conducive circumstances for the less dominant group to transfer their allegiances over to the controlling organisation. In M\&As where this is not the case - for instance, where acquired employees are expected to comply with new routines and ways of working very quickly - then employees may take a very long time to begin to identify with their new employer.

\section{Implications of findings}

The findings presented above are unique in the literature. No other research project has identified such patterns of change in employee identification following M\&A; we show that change in justice and threat play a central role in influencing change in identification and that the context and the nature of the M\&A and its parties are also crucial factors. Whilst Mottola et al. (1997) and Giessner et al. (2006) highlight the fact that merger integration contexts vary and this is likely to influence how employees respond, to date no researchers have shown that the type of entity in an M\&A context interacts with trajectories of employees’ change in identification post M\&A (as we do here). Similarly, although there is some evidence that justice perceptions and other uncertainty linked factors such as 
(dis)continuity (e.g. see Edwards and Edwards, 2012) and perceived differences (see Van Knippenberg et al., 2002) may interact in predicting post M\&A identification, no previous research has shown that a linear change in justice and threat perceptions are linked to a linear change in post M\&A identification (as we do here). A key implication concerns method; our understanding of M\&As will be greatly enhanced by more studies being genuinely longitudinal and containing contrasting research settings.

Finally, the findings that we highlight above - that change in justice and threat are such important predictors of change in identification over time - provides us with particularly useful information that has considerable practical relevance. Most obviously, those responsible for managing integration following an M\&A need to pay particular attention to making sure that procedures put in place/introduced as the integration unfolds are fair and just. In particular, integration managers need to be particularly sensitive to the negative impact that high job threat conditions can have on employees likelihood to willingly integrate with the new post M\&A entity.

A further set of implications flow from our analysis of contrasting contexts. We have shown that the trajectories of identification vary according to the type of M\&A we are examining, and within each M\&A the trajectories can differ between employees in the different parties. This provides incredibly rich information to help M\&A managers understand, predict and explain variation in the time scales and/or patterns of successful integration. Moreover, it is evident that there are not universal tendencies in terms of how employees react to M\&As and the extent to which they identify with the merged firm. While many practitioners that have been through an M\&A before may be able to usefully draw on their experiences, it is by no means likely that employee identification will follow the same trajectory as those they have observed previously. 


\section{Study Limitations and Strengths}

Despite having many strengths, the study does have some limitations. Whilst both M\&A 1 and M\&A 2 measure the same constructs of justice, threat and identification, there are some differences in the three antecedent measures and the M\&A 1 setting utilised a 6item version of the Mael and Ashforth (1992) identification scale rather the 5-item (1995) version (further testing with the identification measure showed that these differences had no material effect on the results, analysis available from the authors on request). The main reason for this is that the two research projects were conducted independently and the researchers collaborated only after they realised the similarities in the two research projects (this realisation occurred after the data had been collected in both cases) and the researchers identified an opportunity to combine projects to compare across the two M\&A contexts. The fit statistics of the measures within the merger study are not quite as strong as those in the acquisition context. Given these differences it is conceivable that differences across the two sets of findings may be due to different measures rather than different settings. However, such a concern is mitigated by the fact that where different measures are used for the same construct (mainly IVs with the T1-T3 change in identification analyses) and the strong relationships found between change of justice and threat with change in identification are remarkably consistent across the two settings. Also, in both contexts, the measurement models consistently show good to acceptable fit in almost all testing.

As some employees who completed the survey at Time 1 did not complete further waves this raises the possibility that the final sample used may have some bias. We followed steps presented by Goodman and Blum, (1996) to assess the presence and effects of any nonrandom aspect to the two samples. In the Merger context, there was no evidence of any systematic non-inclusion bias (no T1 variables used in the merger study predicted whether the respondents continued to complete further surveys) and the samples passed all four of 
Goodman and Blum’s (1996) tests. With the acquisition study, T1 identification predicted continuation (or non-continuation) in the study; a t-test showed that a difference in mean level of T1 identification between those who only completed the first survey and than those who completed a further survey. No significant difference in variances of T1 identification between these two samples, (using the Hays, 1988 method) were found. Importantly ran two regressions (one with the full T1 sample and another with those who completed a further survey) predicting $\mathrm{T} 1$ identification with $\mathrm{T} 1$ justice, $\mathrm{T} 1$ threat and the organisational context dummy. No significant differences were found in results across the two samples (using Fisher's $r$ to $\mathrm{z}$ transformation to compare two sets of results). Thus any bias in the acquisition study is deemed to have no material effect on the analysis and the use of MAR missing data procedures is justified.

Another limitation is that the temporal gaps between the waves were not the same across the two studies. The T1-T2 and T2-T3 time gaps were 12 and 12 months with the acquisition study but 14 and 19 months with the merger. This may have implications for the equivalence of what changes might have been occurring across the two settings. Importantly, despite the differences in timings across the two settings, all hypotheses were still supported by the results and the trajectory tests involved within context comparisons (e.g. larger organizations would show a greater initial growth compared to the smaller organization which would show a steeper increase later in the process). Thus the time gap differences across the two studies does not change our conclusions. Furthermore, there were also differences between the two studies in that the T1 data collection occurred before the merger had formally begun in the M\&A-1 context but the T1 data collection in the acquisition context was formally "post-completion”. Although ideally the timing of the first wave of data collection with both studies would include a "before" context, it is very difficult to gain access to both parties of a private sector acquisition before completion (the deals are usually 
secret due to legal and confidentiality concerns). Thus the project tracks post-acquisition identification with employees at both parties from the point almost immediately after the acquisition occurred, which is the best possible design in the circumstances. Furthermore, both these studies are unique in that they allow us to track change in employee identification across two years post M\&A.

Moreover, the study has a number of strengths which mitigate these limitations, the biggest of which is that it combines two 3-wave longitudinal projects in post M\&A settings. No other study that explores identification post-M\&A tracks employees through and beyond a merger and an acquisition of contrasting types. The current study integrates two such studies and provides rich findings that as yet have not been uncovered in M\&A research. Of course, these two types of M\&A that we focus on by no means cover all possible $M \& A$ settings; to fully understand the possible range of different trajectories and antecedents of identification change following M\&A, future research needs to continue to involve longitudinal research that tracks employees in different post M\&A contexts.

\section{Further research avenues}

A number of findings from the current study help provide a number of possible fruitful avenues to explore with further research. This study helps to begin to shed light on possible trajectories and change in identification/integration following an M\&A in different settings, and we have documented features of integration in the two-year period following two possible contexts. Replicating three-wave longitudinal designs that cover the two year period following M\&A in other possible settings covering M\&A contexts of different types would begin to help develop a framework that could provide M\&A managers with expectations of possible patterns of integration depending upon the strategic context that they are faced with. Other research could draw on Giessner et al.’s (2006) four merger types 
(assimilation, integration-proportionality, integration-equality and transformation) or the merger types set out by Mottolla et al., (1997) of absorb, blend or combine. The current study helps begin to set out such a road map.

One of the central arguments presented in the current paper is that employees' postmerger identification is expected to increase as employees gain a better understanding of the post M\&A entity; we argue this on the basis that conditions of group entativity are considered to be required in order to attract group identification (Hogg, 2007). Although this could be a valid assumption for many M\&A contexts, it may not apply for employees facing serial acquisitions. It is well documented that some firms engage in multiple acquisitions as a business strategy (Schipper and Thompson, 1983; Laamanen \& Keil, 2008), it is likely that additional acquisitions may hamper identification as the nature of the organization and thus the target of identification becomes less clear after each acquisition. In such cases one might argue that entativity conditions and organizational identity stability following integration are very hard to achieve. It would be interesting to study whether our predictions hold for firms continuously acquiring other firms; we might expect a dip or a stall of growth in identification as additional acquisitions hinder the conditions required for identification development. In addition, some further acquisitions may cause threat for particular employees (e.g., for those working in overlapping functions of the newly acquired firm) but not for other groups. Although serial acquisitions have recently been studied in the field of strategic management (e.g., Laamanen \& Keil, 2008) there are no previous studies on the development of employees post-merger identification in the context of serial acquisitions and further research is needed in this area.

Given that change in perceived justice was a particularly strong predictor of postmerger change in identification with our two samples, it would also be interesting to study 
factors that may shape these perceptions in the first instance. For example, Holtz (2014) has recently proposed and found that trust could be seen as a powerful predictor of perceived procedural justice. In M\&A contexts this might imply that initial premerger trust in key decision-makers such as top-management may provide the lens through which employees perceive and evaluate subsequent decisions related to merger process, thereby affecting perceptions of justice. Combined with other possible factors affecting to the temporal changes in justice perceptions (see also Fortin et al., 2014, Monin et al., 2012), this would be a highly fruitful area of future M\&A research.

\section{Conclusion}

As well as being a theoretically interesting topic of study, employee integration is one of the key sources of success or failure post M\&A (Teerikangas \& Very, 2006); given the vast amounts of money organizations often spend in pursuing a merger or acquisition, understanding patterns and antecedents of successful psychological bonding with the newly formed entity is a serious business for organizational decision makers and stakeholders. In this unique combination of studies, we provide valuable insight into the integration process across both an acquisition and merger. Our research indicates that one can make predictions about the expected rates and trajectories of post M\&A integration based on the context of the firms that form the M\&A. We also demonstrate the importance of two factors (justice and threat) shaping the likelihood of employees forging a bond with the post-M\&A entity.

\section{REFERENCES}

Aguilera RV and Dencker JC(2004) The role of human resource management in cross-border mergers and acquisition, International Journal of Human Resource Management, 15, 1355-1370.

Albert S, Ashforth BE and Dutton, JE (2000) Organizational identity and identification: charting new waters and building new bridges. Academy of Management Review, 25: 13-17. 
Amiot CE, Terry DJ and Callan VJ (2007) Status, fairness, and social identification during an intergroup merger. British Journal of Social Psychology, 46: 557-577.

Ashforth BE and Mael F (1989) Social identity theory and the organization. Academy of Management Review, 14: 20-39.

Bardi A, Guerra VM and Ramdeny GSD (2009) Openness and ambiguity tolerance: Their differential relationships to well-being in the context of an academic life transition. Personality and Individual Differences, 47: 219-223.

Bartel JA, Douwes, R, de Jong M, and Pruyn A (2009) Organizational identification during a merger: Determinants of employees expected identification with the new organization, British Journal of Management, 17, S49-S67.

Bartels JA, Pruyn and M. de Jong (2009) Employee identification before and after an internal merger: A longitudinal analysis. Journal of Occupational and Organizational Psychology, 82, 113128

Baumeister RF and Leary MR (1995) The need to belong: Desire for interpersonal attachments as a fundamental human motivation. Psychological Bulletin, 117: 497-529.

Boen F, Vanbeselaere N and Cool M (2006) Group status as a determinant of organizational identification after a takeover: A social identity perspective. Group Processes \& Intergroup Relations, 9: 547-560.

Bollen, KA, and Curran PJ (2006) Latent curve models: A structural equation approach. Hoboken, NJ: Wiley.

Boswell WR, Shipp AJ, Payne SC. and Culbertson SS (2009) Changes in newcomer job satisfaction over time: examining the pattern of honeymoons and hangovers. Journal of Applied Psychology, 94(4), 844-858.

Boswell,WR. Boudreau JW and Tichy, J (2005) The relationship between employee job change and job satisfaction: the honeymoon-hangover effect. Journal of applied psychology, 90(5), 882892.

Buono, PJ, Bowditch JL and Lewis JW (1985) When Cultures Collide: the Anatomy of a Merger, Human Relations, Vo. 38, Issue 5: 477-500.

Byrne ZS (1999) Procedural and Interactional Justice: Understanding Multilevel Outcomes. Unpublished Master Thesis. Colorado: Colorado State University.

Cartwright S and Cooper CL (1993) The psychological impact of merger and acquisition on the individual: A study of building society managers. Human Relations, 46: 327-347.

Collins LM, Schafer JL, and Kam CM (2001) A comparison of inclusive and restrictive strategies in modern missing-data procedures. Psychological Methods, 6, 330-351.

Dooley KJ and Zimmerman BJ (2003) Merger as marriage: Communication issues in postmerger integration. Health Care Management Review, 28(1), pp.55-67. 
Duncan TE, Duncan SC, and Strycker LA (2006) An introduction to latent variable growth curve modeling: Concepts, issues and applications. Mahwah, NJ: Erlbaum.

Edwards MR and Edwards T (2012) Procedural justice and post acquisition identification: the moderating effects of job and organizational identity related discontinuity. Human Resource Management Journal, 22: 109-128.

Folger R and Cropanzano R (1998) Organizational justice and human resource management. Beverly Hills, CA: Sage.

Fortin M, Cojuharenco I, Patient DL and German H (2014) It's time for justice. Journal of Organizational Behavior, Online First, DOI: 10.1002/job.1958

Fugate M, Prussia GE and Kinicki AJ. (2012) Managing employee withdrawal during organizational change: The role of threat appraisal. Journal of Management, 38: 890-914.

Gleibs IH, Mummendey A and Noack P (2008) Predictors of change in post-merger identification during a merger process: A longitudinal study. Journal of Personality and Social Psychology, 95: 1095-1112.

Gleibs IH, Noack P, Mummendey A (2009) We are still better than them: A longitudinal field study of ingroup favouritism during a merger, European Journal of Social Psychology, 40, 819-836.

Giessner SR, Horton KE and Humborstad SIW (2016) Identity management during organizational mergers: Empirical insights and practical advice. Social Issues and Policy Review, 10(1), 47-81.

Giessner SR, Viki GT, Otten S, Terry DJ and Tauber S (2006) The challenge of merging: Merger patterns premerger status, and merger support. Personality and Social Psychology Bulletin, 32: 339-352.

Giessner SR (2011) Is the merger necessary? The interactive effect of perceived necessity and sense of continuity on post-merger identification. Human Relations, 64: 1079-1098.

Goodman JS and Blum TC (1996) Assessing the non-random sampling effects of subject attrition in longitudinal research, Journal of Management, 22, 627-652.

Guerrero S (2008) Changes in employees' attitudes at work following an acquisition: a comparative study by acquisition type. Human Resource Management Journal, 18: 216-236.

Hays WL (1988) Statistics (4th-ed.) Florida: Holt, Rinehart \& Winston

Hogg MA (2007) Uncertainty-identity theory. Advances in Experimental Social Psychology, 39: 69126.

Holtz BC (2014) From first impression to fairness perception: Investigation the impact of initial trustworthiness beliefs. Personnel Psychology, 00: 1-48.

Hornsey MJ and Hogg MA (2000) Assimilation and Diversity: An Integrative Model of Subgroup Relations. Personality and Social Psychology Review, 4: 143-156.

Hogg MA and Adelman J (2013) Uncertainty-Identity Theory: Extreme Groups, Radical Behavior, and Authoritarian Leadership. Journal of Social Issues, 69: 436-454. 
Laamanen T and Keil T (2008) Performance of serial acquirers: toward an acquisition program perspective. Strategic Management Journal, 29: 663-672.

Lazarus RS and Folkman S (1984) Stress, appraisal, and coping. New York: Springer.

Lipponen J, Olkkonen M and Moilanan M (2004) Perceived procedural justice and employee responses to an organizational merger. European Journal of Work and Organizational Psychology, 13: 391-413.

Little, RJA and Rubin, DB (2002) Analysis with Missing Data (2nd Edition) Wiley: NJ.

Lupina-wegener A, Drzensky F, Ullrich J and Van Dick R (2013) Focusing on the bright tomorrow? A longitudinal study of organizational identification and projected continuity in a corporate merger. British Journal of Social Psychology, 53: 752-772.

Mael, FA and Ashforth, BE (1992) Alumni and their alma mater: A partial test of the reformulated model of organizational identification. Journal of Organizational Behavior,13, 103-123.

Mael FA and Ashforth BE (1995) Loyal from day one: biodata, organizational identification and turnover among newcomers. Personnel Psychology, 48: 309-333.

Michel A, Stegmaier R and Sonntag K (2010) I Scratch Your Back - You Scratch Mine. Do Procedural Justice and Organizational Identification Matter for Employees’ Cooperation During Change? Journal of Change Management 10: 41-59.

Monin P, Noorderhaven N, Vaara E and Kroon D (2013) Giving sense to and making sense of justice in post-merger integration. Academy of Management Journal, 56: 256-284.

Moorman RH (1991) Relationship between organizational justice and organizational citizenship behaviors: Do fairness perceptions influence employee citizenship? Journal of Applied Psychology, 76: 845-855.

Mottola GR, Bachman BA, Gaertner SL and Dovidio JF (1997) How groups merge: The effects of merger integration patterns on anticipated commitment to the merger organization. Journal of Applied Social Psychology, 27: 1335-1358.

Newsom JT, (2015) Longitudinal Structural Equation Modelling: A Comprehensive Introduction, Routledge,

Ng TWH, Feldman DC, and Lam, SSK (2010) Psychological contract breaches, organizational commitment, and innovation-related behavior: A latent-growth modeling approach. Journal of Applied Psychology, 95, 744-751.

Ng TWH and Feldman DC (2013) Community embeddedness and work outcomes: The mediating role of organizational embededdness. Human Relations, Online:First, doi: 10.1177/0018726713486946

Pentz, MA, and Chou, CP (1994) Measurement invariance in longitudinal clinical research assuming change from development and intervention. Journal of Consulting and Clinical Psychology, 62, 450-462

Ployhart, RR, and Vandenberg RJ. (2010) Longitudinal research: The theory, design and analysis of change, Journal of Management, 36, 94-120. 
Schafer JL and Graham JW (2002) Missing data: Our view of the state of the art. Psychological Methods, 7, 147-177.

Scheck CL and Kinieki AJ (2000) Identifying antecedents of coping with an organizational acquisition: A structural assessment. Journal of Organizational Behavior, 21: 627-648.

Schipper K and Thompson R (1983) Evidence in the capitalized value of merger activity for acquiring firms. Journal of Financial Economics, 11: 85-119.

Tajfel H and Turner JC (1979) An integrative theory of intergroup conflict. In W. G. Austin \& S. Worchel (Eds.), The social psychology of intergroup relations (33-47). Monterey, CA: Brooks-Cole.

Teerikangas S and Very P (2006) The Culture-Performance Relationship in M\&A: From Yes/No to How, British Management Journal, 17, 31-48.

Terry DJ, Callan VJ and Carey CJ (2001) Employee adjustment to an organizational merger: An intergroup perspective. Personality and Social Psychology Bulletin, 27: 267-280.

Terry DJ, Callan VJ, and Sartori G (1996) A test of a stress-coping model of adjustment to a largescale organizational change, Stress Medicine, 12, pp.105-122.

Terry DJ and Callan VJ (1998) In-group bias in response to an organizational merger. Group Dynamics: Theory, Research, Practice, 2: 67-81.

Tyler T and Blader S (2003) The group engagement model: Procedural justice, social identity theory, and cooperative behaviour. Personality and Social Psychology Review, 7: 349-361.

Tyler TR and De Cremer D (2005) Process-based leadership: Fair procedure and reactions to organizational change. Leadership Quarterly, 16: 529-545.

Van den Bos K and Lind EA (2002) Uncertainty management by means of fairness judgments. In MP Zanna (Ed.), Advances in experimental social psychology, 34:1-60. Boston, MA.

Van Dick R, Wagner U and Lemmer G (2004) The winds of change. Multiple identifications in the case of organizational mergers. European Journal of Work and Organizational Psychology, 13: $121-138$.

Van Dick R, Ullrich J and Tissington PA (2006) Working ‘under a black cloud: Sustaining organizational identification after a merger. British Journal of Management, 17: 69-79.

Van Knippenberg D, Van Knippenberg B and Monden L, de Lima F (2002) Organizational identification after a merger: a social identity perspective. British Journal of Social Psychology, 41: 233-252. 
Table 1: Correlations between all variables, reliability statistics and means with the 3-wave merger panel sample M\&A 1 )

\begin{tabular}{|c|c|c|c|c|c|c|c|c|c|c|c|c|}
\hline & $\mathrm{Mn}$ & S.D. & 1. & 2. & 3. & 4. & 5. & 6. & 7. & 8. & 9. & 10. \\
\hline 1. OID T1 & 2.64 & .72 & $.81 \dagger$ & & & & & & & & & \\
\hline 2. OID T2 & 2.79 & .79 & $.70^{* * * *}$ & .84 & & & & & & & & \\
\hline 3. OID T3 & 2.91 & .84 & $.57 * * *$ & $.68 * * *$ & .85 & & & & & & & \\
\hline 4. Justice T1 & 2.78 & .66 & $.42^{* * *}$ & $.29 * * *$ & $.24 * * *$ & .90 & & & & & & \\
\hline 5. Justice T2 & 2.53 & .69 & $.37 * * *$ & $.42 * * *$ & $.35 * * *$ & $.63^{* * *}$ & .89 & & & & & \\
\hline 6. Justice T3 & 2.56 & .71 & $.24^{* * *}$ & $.29 * * *$ & $.42 * * *$ & $.47^{* * *}$ & $.67^{* * *}$ & .90 & & & & \\
\hline 7. Threat $\mathrm{T} 1$ & 2.39 & .75 & $-.22 * * *$ & $-22 * * *$ & $-.12 *$ & $-.35 * * *$ & $-.31^{* * *}$ & $-.21 * * *$ & .73 & & & \\
\hline 8. Threat $\mathrm{T} 2$ & 2.55 & .84 & $-.14^{* *}$ & $-.20 * *$ & $-.19^{* *}$ & $-.28^{* * *}$ & $-.43^{* * *}$ & $-.34 * *$ & $.52^{* * *}$ & .80 & & \\
\hline 9. Threat T3 & 2.64 & .87 & $-.14^{* *}$ & $-.22 * * *$ & $-.35 * * *$ & $-.22 * * *$ & $-.31^{* * *}$ & $-.45^{* * *}$ & $.39 * * *$ & $.56^{* * *}$ & .79 & \\
\hline $\begin{array}{l}\text { 10. Small V Large } \\
\text { Organization } \dagger \dagger\end{array}$ & 1.68 & .47 & -.01 & $.13^{*}$ & .02 & .05 & $.13^{*}$ & .02 & -.10 & -.06 & -.03 & . \\
\hline
\end{tabular}


Table 2: Correlations between all variables, reliability statistics and means with the 3-wave acquisition panel sample M\&A-2)

\begin{tabular}{|c|c|c|c|c|c|c|c|c|c|c|c|c|}
\hline & Mn & S.D. & 1. & 2. & 3. & 4. & 5. & 6. & 7. & 8. & 9. & 10. \\
\hline 1. OID T1 & 3.31 & .71 & $.82 \dagger$ & & & & & & & & & \\
\hline 2. OID T2 & 3.41 & .62 & $.63 * * *$ & .78 & & & & & & & & \\
\hline 3. OID T3 & 3.44 & .67 & $.58 * * *$ & $.70 * * *$ & .83 & & & & & & & \\
\hline 4. Justice T1 & 3.26 & .68 & $.37 * * *$ & $.27 * * *$ & $.27^{* * *}$ & .88 & & & & & & \\
\hline 5. Justice T2 & 3.37 & .70 & $.32 * * *$ & $.46^{* * *}$ & $.42^{* * *}$ & $.60 * * *$ & .87 & & & & & \\
\hline 6. Justice T3 & 3.41 & .70 & $.16^{*}$ & $.28 * * *$ & $.40^{* * *}$ & $.44 * * *$ & $.64^{* * *}$ & .89 & & & & \\
\hline 7. Threat T1 & 2.71 & .96 & $-.17^{*}$ & -.14 & -.06 & $-.19 * *$ & $-.18^{*}$ & $-.15^{*}$ & .87 & & & \\
\hline 8. Threat T2 & 2.40 & .77 & -.12 & $-.21^{* *}$ & $-.16^{*}$ & -.01 & $-.24 * *$ & $-.22 * *$ & $.45^{* * *}$ & .82 & & \\
\hline 9. Threat T3 & 2.32 & .78 & -.06 & $-.20 * *$ & $-.29 * *$ & $-.17^{*}$ & $-.23 * *$ & $-.35^{* * *}$ & $.40^{* * *}$ & $.44 * * *$ & .90 & \\
\hline 10. AcqVAcq'd †† & 1.35 & .48 & $-.25 * * *$ & -.11 & -.02 & .05 & .08 & .10 & $.40^{* * *}$ & $.27 * * *$ & .13 & - \\
\hline
\end{tabular}

$\mathrm{N}=187$

${ }^{*} \mathrm{p}<0.05,{ }^{* *} \mathrm{p}<0.01, * * * \mathrm{p}<0.001$

$\dagger$ Cronbach Alpha Coefficients on the Diagonal

$\dagger †$ Coded as $1=$ Acquiring firm and $2=$ Acquired firm 
Figure 1: Mean level changes in identification across time: Comparing large versus small organization type in a merger context (M\&A-1)

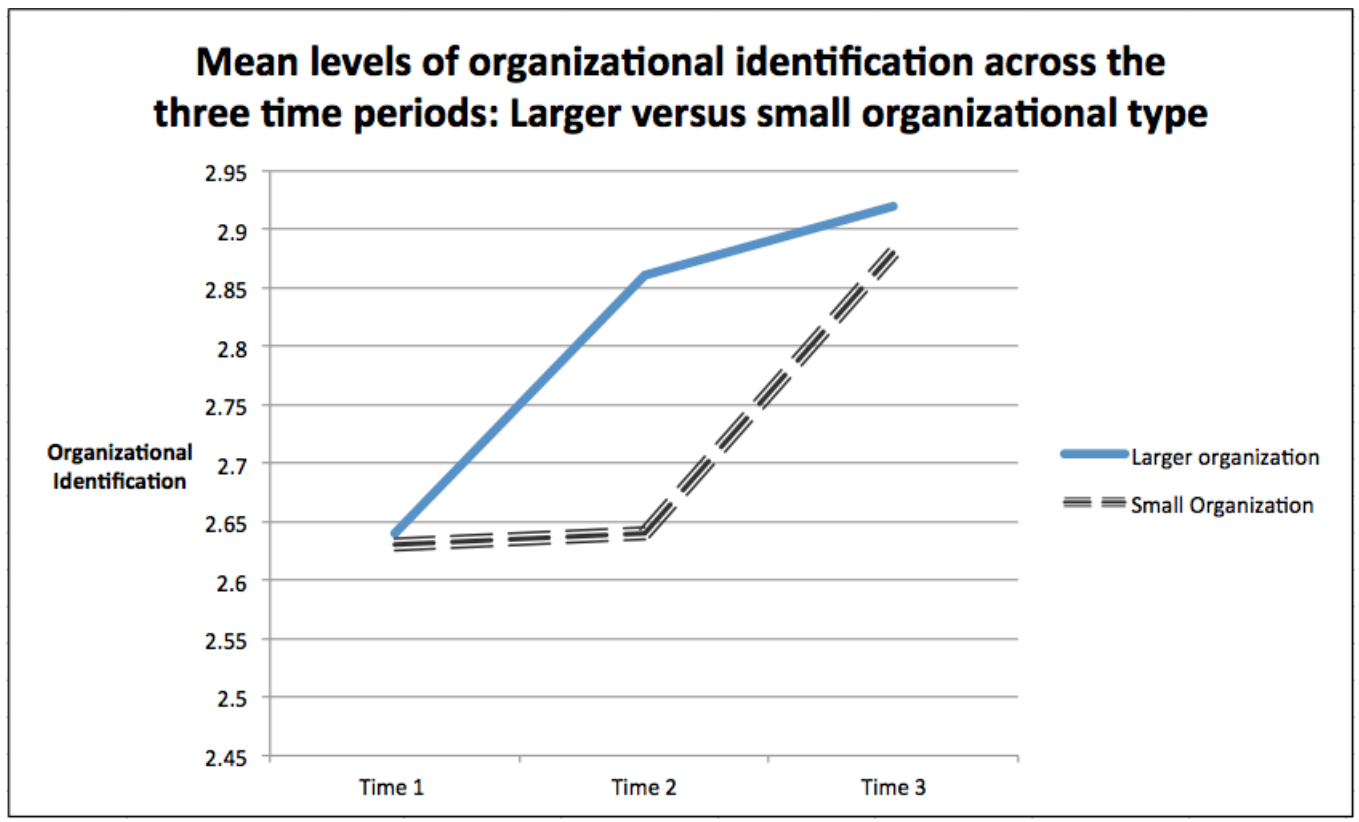

Figure 2: Mean level changes in identification across time: Comparing acquired versus acquirer organization type in an acquisition context (M\&A-2)

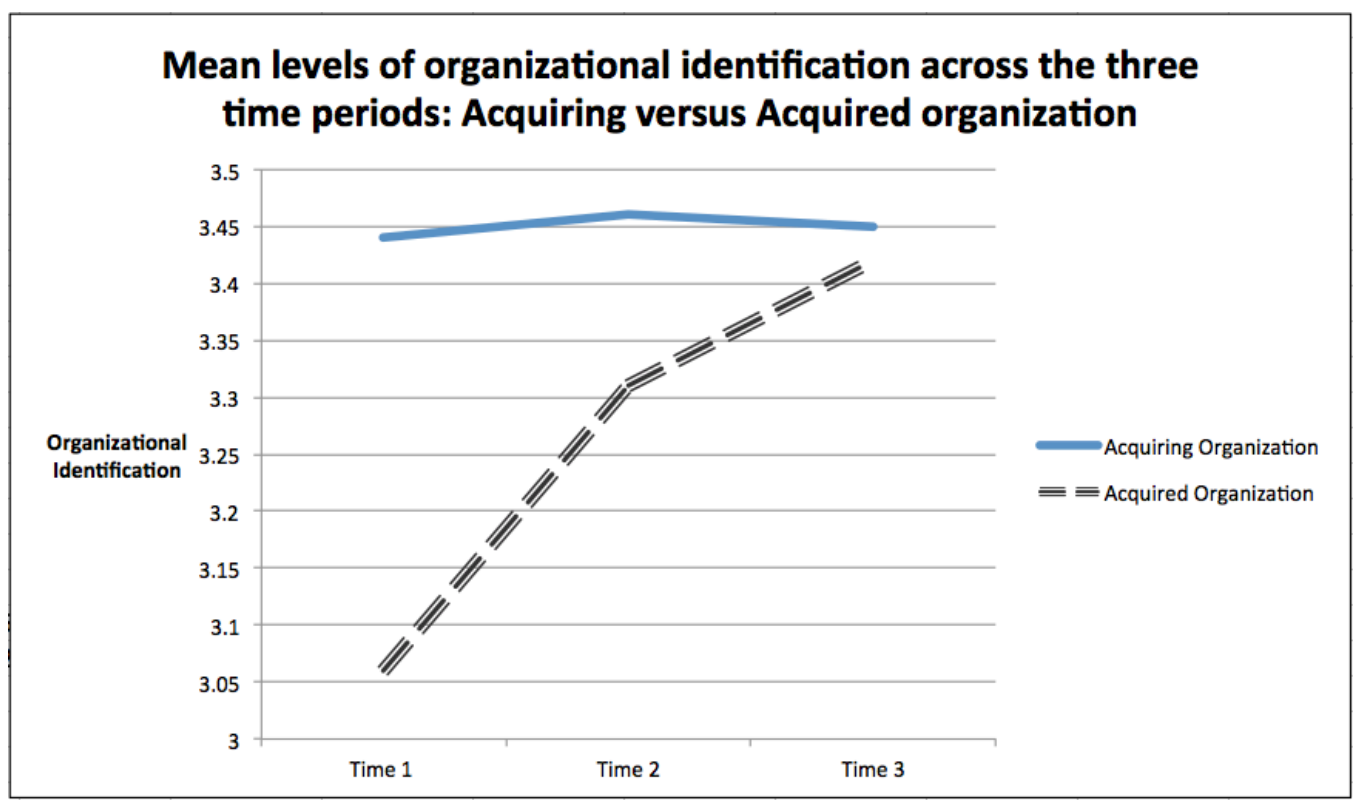


Table 3: Unvariate Latent Growth Models (LGM): T1, T2 and T3 growth parameter estimates in a merger context (M\&A-1)

\begin{tabular}{|c|c|c|c|c|c|}
\hline \multirow[b]{2}{*}{ Parameter } & \multicolumn{2}{|c|}{ Initial Status (IS) } & \multicolumn{2}{|c|}{$\begin{array}{c}\text { Change }(\mathrm{CH}) \\
\text { Linear Increase or } \\
\text { Decrease }\end{array}$} & \multirow[b]{2}{*}{$\begin{array}{c}\text { Covariance } \\
\text { of Initial } \\
\text { Status with } \\
\text { CHange } \\
\text { slope } \\
\text { IS }<->\text { CH } \\
\left(\sigma_{\text {Is-CH }}\right) \\
\end{array}$} \\
\hline & $\begin{array}{c}\text { Mean } \\
\text { Initial } \\
\text { Status } \\
\\
\left(\mu_{\mathrm{IS}}\right)\end{array}$ & $\begin{array}{l}\text { Individual } \\
\text { Variance } \\
\text { Of Initial } \\
\text { Status }\end{array}$ & $\begin{array}{c}\text { Mean } \\
\text { Rate of } \\
\text { Increase or } \\
\text { Decrease } \\
\left(\mu_{\mathrm{CH}}\right)\end{array}$ & $\begin{array}{c}\text { Individual } \\
\text { Variance } \\
\text { of Increase } \\
\text { or } \\
\text { Decrease } \\
\left(\sigma_{\mathrm{cH}}\right)\end{array}$ & \\
\hline $\begin{array}{l}\text { Identification: } \\
\text { - With Merged Entity } \\
\text { Perceived Justice } \\
\text { Perceived Threat }\end{array}$ & $\begin{array}{l}2.70^{* * *} \\
2.77^{* * *} \\
2.37^{* * *} \\
\end{array}$ & $\begin{array}{l}0.41^{* * *} \\
0.31^{* * *} \\
0.33^{* * *}\end{array}$ & $\begin{array}{r}0.12^{* * *} \\
-0.11^{* * *} \\
0.11^{* * *} \\
\end{array}$ & $\begin{array}{l}0.05^{* * *} \\
0.05^{* * *} \\
0.04^{* *} \\
\end{array}$ & $\begin{array}{l}-0.01 \\
-0.03 * \\
-0.00 \\
\end{array}$ \\
\hline
\end{tabular}

$\mathrm{N}=938{ }^{*} \mathrm{p}<0.05,{ }^{* *} \mathrm{p}<0.01,{ }^{* * *} \mathrm{p}<0.001$

Table 4: Latent Growth Models (LGM): T1, T2 and T3 growth parameter estimates in the acquisition context (M\&A-2)

\begin{tabular}{|c|c|c|c|c|c|}
\hline \multirow[b]{2}{*}{ Parameter } & \multicolumn{2}{|c|}{ Initial Status (IS) } & \multicolumn{2}{|c|}{$\begin{array}{c}\text { Change (CH) } \\
\text { Linear Increase or } \\
\text { Decrease } \\
\end{array}$} & \multirow[b]{2}{*}{ 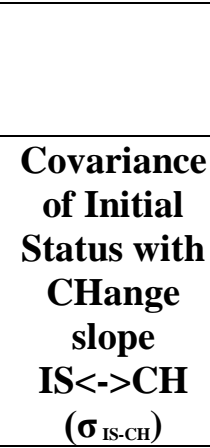 } \\
\hline & $\begin{array}{c}\text { Mean } \\
\text { Initial } \\
\text { Status } \\
\\
\left(\mu_{\mathrm{IS}}\right)\end{array}$ & $\begin{array}{c}\text { Individual } \\
\text { Variance } \\
\text { Of Initial } \\
\text { Status } \\
\left(\sigma_{\text {Is }}\right) \\
\end{array}$ & $\begin{array}{c}\text { Mean } \\
\text { Rate of } \\
\text { Increase or } \\
\text { Decrease } \\
\\
\left(\mu_{\mathrm{CH}}\right) \\
\end{array}$ & $\begin{array}{c}\begin{array}{c}\text { Individual } \\
\text { Variance } \\
\text { of Increase } \\
\text { or }\end{array} \\
\text { Decrease } \\
\left(\sigma_{\mathrm{cH}}\right) \\
\end{array}$ & \\
\hline $\begin{array}{l}\text { Identification: } \\
\text { - Post Acquisition } \\
\text { Perceived Justice } \\
\text { Perceived Threat } \\
\end{array}$ & $\begin{array}{l}3.26^{* * * *} \\
3.25^{* * * *} \\
2.71^{* * *}\end{array}$ & $\begin{array}{l}0.40^{* * *} \\
0.31^{* * * *} \\
0.53^{* * *}\end{array}$ & $\begin{array}{l}0.06^{* *} \\
0.07 * * \\
-0.18^{* * *}\end{array}$ & $\begin{array}{l}0.05^{* * *} \\
0.05^{* *} \\
0.06^{* * *} \\
\end{array}$ & $\begin{array}{l}-0.06 * * * \\
-0.03 \\
-0.13^{* * *}\end{array}$ \\
\hline
\end{tabular}

$\mathrm{N}=346$

${ }^{*} \mathrm{p}<0.05,{ }^{* *} \mathrm{p}<0.01,{ }^{* * *} \mathrm{p}<0.001$ 
Table 5: Standardised coefficients for main structural paths in the multivariate LGM including organisational (large versus small) group predictor of identification Initial Status and CHange in the merger context (M\&A-1)

\begin{tabular}{lcc}
\hline & $\begin{array}{c}\text { DV } \\
\text { Merged University } \\
\text { Identification } \\
\text { Initial Status (IS) }\end{array}$ & $\begin{array}{c}\text { DV } \\
\text { Merged University } \\
\text { Identification Change (CH) } \\
\text { T1,T2,T3 Linear Increase }\end{array}$ \\
\hline Parameter & & \\
\hline Org Small V Large & -0.07 & 0.05 \\
Justice Initial Status & $0.57^{* * *}$ & 0.09 \\
Justice Change (rate of increase) & - & $0.76^{* * *}$ \\
Threat Initial Status & -0.01 & 0.03 \\
Threat Change (rate of decrease) & - & $-0.67^{* * *}$ \\
\hline
\end{tabular}

Table 6: Standardised coefficients for main structural paths in the multivariate LGM including organisational (acquirer $\mathbf{V}$ acquired) group predictor of identification Initial Status and CHange in the acquisition context (M\&A-2)

\begin{tabular}{lcc}
\hline & $\begin{array}{c}\text { DV } \\
\text { Post-Acquisition } \\
\text { Identification } \\
\text { Initial Status (IS) }\end{array}$ & $\begin{array}{c}\text { DV } \\
\text { Post-Acquisition } \\
\text { Identification Change (CH) } \\
\text { T1,T2,T3 Linear Increase }\end{array}$ \\
\hline Parameter & & \\
\hline Acquirer V Acquired & $-0.40^{* * *}$ & $0.46^{* * *}$ \\
Justice Initial Status & $0.57^{* * *}$ & -0.17 \\
Justice Change (rate of increase) & - & $0.73^{* * *}$ \\
Threat Initial Status & 0.01 & $-0.50^{* *}$ \\
Threat Change (rate of decrease) & - & $-0.63^{* *}$ \\
\hline $\mathrm{N}=346,{ }^{*}<0.05,{ }^{* *} \mathrm{p}<0.01,{ }^{* * *}<0.001$ & &
\end{tabular}

